\title{
Potential Benefits of Remote Continuous Care for Depression
}

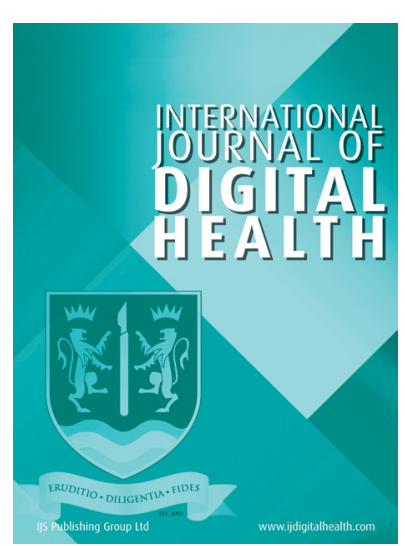

\author{
VALERIE L. FORMAN-HOFFMAN (1) \\ JOSEPH C. KVEDAR (D) \\ KRISTIAN RANTA (1)
}

*Author affiliations can be found in the back matter of this article

\section{ABSTRACT}

Depression is a burdensome and costly disease. Treatment is not sought by over half of depressed patients, and many who suffer remain depressed despite treatment. Furthermore, there is no single treatment efficacious for all patients, with optimal outcomes precluded by access, adherence, and patient satisfaction issues. The recent proliferation of telehealth solutions has increased access to care, especially during the COVID pandemic, but problems with several of its traditional types of delivery models still exist. Rather than the provision of traditional episodic mental health care, creative mental health solutions that can provide continuous care with frequent patientprovider interactions are urgently needed. This Perspective explores how digital health solutions enable the provision of continuous types of remote care to provide relief for some of the access and capacity problems exacerbated by requirements for face-toface types of care.

CORRESPONDING AUTHOR:

\section{Valerie Forman Hoffman, PhD, MPH}

Chief Research Officer, Meru Health, Inc., 19 South B, Suite 3, San Mateo, CA 94401

valerie@meruhealth.com

KEYWORDS:

internet intervention; digital technology; depression; anxiety; perspective; viewpoint

TO CITE THIS ARTICLE: Forman-Hoffman VL, Kvedar JC, Ranta K. Potential Benefits of Remote Continuous Care for Depression. International Journal of Digital Health. 2021; 1(1): 15, 1-6. DOI: https://doi. org/10.29337/ijdh.39 
Depression has become one of the most burdensome diseases in the world in terms of societal and financial costs [1-5]. Since the COVID-19 global pandemic began in 2020, reports have indicated upwards trends, with one finding more than a 3 -fold increase in the prevalence of depression symptoms [6]. In light of these increases and the mental health effects of prolonged periods of social isolation [7], quick access to effective depression care is critically important.

Myriad challenges have led to poor outcomes when treating depression. For one, there is no definitive type of standard depression care, with some guidelines recommending psychotherapy and others naming pharmacotherapy as first-line depression agents [810]. Recent meta-analyses have indicated less-thanoptimal response rates of $41 \%$ for psychotherapy [11] and no significant differences in response between psychotherapy and pharmacotherapy depression interventions [12]. Second, optimal outcomes have been precluded by issues with care access, adherence, and patient satisfaction, which increase dropout rates [13-16]. Some who suffer from depression know they need care but do not want others to know they are in treatment, while others do not have time to devote to treatment or even know where to go to receive services [17]. Others cite treatment costs and issues with transportation or childcare as main barriers to seeking care. When mental health care is sought, some patients have to wait weeks or even months to receive it [18-19]. And when care is finally received, many interventions do not incorporate relapse prevention techniques, which can reduce long-term sustainability of any treatment gains [20-23]. Finally, many pharmacotherapy treatments have associated side effects such as sleep issues, weight changes, eating difficulties, pain, and sexual functioning problems [24] that negatively affect adherence and, ultimately, increase drop-out rates [25-26].

The recent proliferation of telehealth solutions has provided options to brick-and-mortar facilities, especially during the COVID pandemic when stay-at-home orders reduced the ability to have in-person visits [27-28]. These interventions combat one barrier to carestigma-by allowing for discreet treatment that can reduce feelings of shame associated with seeking care. Some of these telehealth solutions, however, still rely on face-to-face patient-provider interactions. For example, some telehealth visits involve synchronous care via meeting with either a primary care provider (PCP) or a specialty mental health provider where either face-toface therapy or a prescription for antidepressants (or both) is provided. While helping to solve an important remote access issue during times when in-person visits cannot occur, these types of synchronous telehealth visits still only provide episodic treatment in the current healthcare environment. This type of face-to-face telehealth visit provides care at scheduled appointment times but fails to allow for easy between-appointment monitoring of symptom improvement and, for those on antidepressants, side effect onset or worsening without scheduling and attending another episodic appointment. There is a potential for patients treated by telehealth face-to-face PCPs or specialty mental health providers to struggle in the weeks or months between visits without any provider awareness.

Digital health is one feasible way to deliver mental health solutions that allow for enhanced access to frequent patient-provider interactions [29]. Rather than providing care only at scheduled appointment times, the interactions can happen more continuously whenever the need arises. This is particularly true for asynchronous solutions. In these types of interventions, patients can complete various online exercises (e.g., psychoeducational lessons with questions posed to the patient, meditation or biofeedback practices, etc.) and the therapist can provide written feedback on those exercises. Then, the patient can read the therapist's messages when convenient and, if needed, return a message back to the therapist.

Although all types of digital solutions may solve access issues, these types of continuous, asynchronous solutions also have the potential to relieve some of the capacity problems exacerbated by face-to-face types of care. Digital interventions that employ asynchronous care also can efficiently address capacity issues faced in many areas of the U.S that suffer from shortages in mental health providers and might reduce the burden felt by primary care providers (PCPS) who often have to treat patients with mental health issues themselves [3031]. Although some argue that digital solutions might increase the number of depressed patients accessing care and thus raise the amount of overall mental health spending, effective digital strategies that move patients from being depressed to not depressed could lead to more than $\$ 6000$ per patient per year in total healthcare expenditure savings [32-33]. Even digital interventions supported in some ways by trained mental health providers can be scalable and cost-effective with careful considerations to automating portions of the treatment asynchronously and reducing the time-per-patient to a minimally adequate level.

Quite strikingly, supported digital mental health solutions provide opportunities to "touch" the patient on a frequent basis that are not afforded in the current structure of face-to-face episodic mental health care, even that provided by telehealth. This model of continuous care takes the merits of the supportive accountability model [34]-in which human support provides patients with a "check-in,"-one step further. In contrast to the traditional episodic model, albeit inperson or delivered via telehealth, continuous care provided by supportive therapists may improve rates of program completion and engagement and, thus, 
lead to better clinical outcomes [35]. A review of digital mental health interventions found dropout rates lower for therapist-supported (TS; 28\%) and administrativesupported (AS; 38.4\%) treatments as compared with non-supported (NS; 74\%) treatments [36].

In addition, adherence to and patient satisfaction with supported digital mental health interventions appears high, although many digital health intervention trials fail to report these metrics [37]. One therapist-supported digital health intervention that provides this model of "continuous care" asynchronously reports that patients with at least moderate depressive symptom scores at baseline (PHQ-9 > = 10) engage with the program an average of 3.9 days per week during their 8- to 12week program and that only about $19.6 \%$ drop out [38]. Patients in this model of care get immediate feedback in real time-they don't have to wait to see their mental health provider for weeks or months to check-in with them and discuss strategies that are working and what aspects require more attention. Despite the remote provision of care, the therapeutic alliance created is robust and at least as strong as that provided by interventions delivered face-to-face [39].

These gains in adherence and satisfaction translate to improvements in outcomes. A review of digital mental health interventions found significantly better betweengroup effect sizes for therapist-supported (TS) treatments $(d=0.78)$ and administrative-supported (AS) treatments $(d=0.58)$ than non-supported (NS) treatments ( $d=0.36)$ [36]. Considering these effect sizes in light of real-world psychotherapy and pharmacotherapy studies, with response (defined as at least $50 \%$ reduction in symptoms) rates of $36 \%$ at 24 -week follow-up in one study of adult depressed patients treated by psychiatrists [40] and, in another study, of $25.4 \%$ response at 6-month follow-up among public sector depressed outpatients treated by a medication algorithm [41] strengthens the case for preferential use of a continuous care model afforded by digital health solutions.

The continuous care aspect of digital mental health interventions also provides real-time data that patients want [42] and providers can use to monitor patient symptoms and provide timely feedback to increase the likelihood of having a good outcome. This method of data collection also allows providers to quickly respond to common safety issues-like deteriorating mental health, suicidality, and onset of psychotic symptoms during the intervention [43]. As the future of medicine becomes more empowered by digital tools and solutions, data collected via digital interventions can be analyzed using cutting edge methodologies. For example, recent advances in artificial intelligence methods including machine learning tools and techniques and natural language processing may lead to early detection of behavioral patterns that could improve outcomes via the ability to individualize and personalize key components of the intervention [44]. Methods being used in several ground-breaking efforts to develop predictive models that detect occurrences of suicide attempt [45], the onset of psychosis [46], and violent behaviors [47] from analyses of speech and written text can be applied to improving depression care with data collected by appbased interventions.

More rigorous studies such as well-designed randomized controlled trials are critically needed [29]. For example, a head-to-head study that compares the efficacy of supported digital health interventions that provide continuous care and more traditional, episodic types of care such as face-to-face therapy and/or pharmacotherapy would illuminate differences between care types. These studies should employ well-known, reliable symptom measures such as the Patient Health Questionnaire-9 item scale [48] as well as diagnostic information from semi-structured clinical interviews such as the Mini International Neuropsychiatric Interview (MINI) [49]. Ideally, additional studies that compare interventions systematically are needed to calculate whether the digital health solutions affect the number able to initiate treatment, to help understand how patient-provider interactions may impact completion rates, and to determine cost-effectiveness [50]. Now, more than ever in our post-pandemic world filled with the aftereffects of social isolation, we need to embrace supported digital depression interventions that enable the delivery of continuous care and devote our resources towards developing them.

\section{COMPETING INTERESTS}

Dr. Forman-Hoffman is employed as the Chief Research Officer at Meru Health, Inc., receives salary from the company and owns options of the company. Dr. Kvedar is on the Advisory Boards of LuminDx (also owns stock) and Res App Health (also owns stock and draws consulting fees), Flare Capital, and Good Rx, serves as a consultant and draws a consultant fee from Boston Microfluidics, and owns stock in MD Revolution, b.well (also serves on Board of Directors), MobileHelp (also serves on Board of Directors), NuRx (also draws a consulting fee and serves on a board sub-committee) and FDNA (also serves as an advisor). Mr. Ranta serves as the Chief Executive Officer (CEO) at Meru Health, Inc., owns a large share of stocks, and raises salary from the company.

\section{AUTHOR AFFILIATIONS}

Valerie L. Forman-Hoffman, PhD, MPH (D) orcid.org/0000-

0001-7885-8873

Meru Health Inc., San Mateo, CA, USA

Joseph C. Kvedar, MD (D) orcid.org/0000-0002-7517-2291

Partners Healthcare, Harvard Medical School, Boston, MA, USA

Kristian Ranta, MSc (D) orcid.org/0000-0002-2475-9009

Meru Health Inc., San Mateo, CA, USA 


\section{REFERENCES}

1. Cai Q, Sheehan JJ, Wu B, Alphs L, Connolly N, Benson C. Descriptive analysis of the economic burden of treatment resistance in a major depressive episode. Current Medical Research and Opinion. 2020; 36(2): 329-335. DOI: https:// doi.org/10.1080/03007995.2019.1671087

2. Chow W, Doane MJ, Sheehan J, Alphs L, Le H. Economic burden among patients with major depressive disorder: an analysis of healthcare resource use, work productivity, and direct and indirect costs by depression severity. American Journal of Managed Care. 2019; 16: e188-e196.

3. Liu Q, He H, Yang J, Feng X, Zhao F, Lyu J. Changes in the global burden of depression from 1990 to 2017: Findings from the Global Burden of Disease study. Journal of Psychiatric Research. 2020; 126: 134-140. DOI: https://doi. org/10.1016/j.jpsychires.2019.08.002

4. Sussman M, O'Sullivan AK, Shah A, Olfson M, Menzin J. Economic burden of treatment-resistant depression on the US Health Care System. Journal of Managed Care \& Specialty Pharmacy. 2019; 25(7): 823-835. DOI: https://doi. org/10.18553/jmcp.2019.25.7.823

5. Vos T, Barber RM, Bell B, Bertozzi-Villa A, Biryukov S, Bolliger I, Charlson F, Davis A, Degenhardt L, Dicker D, Duan L. Global, regional, and national incidence, prevalence, and years lived with disability for 301 acute and chronic diseases and injuries in 188 countries, 1990-2013: a systematic analysis for the Global Burden of Disease Study 2013. The Lancet. 2015 Aug 22; 386(9995): 743-800.

6. Ettman CK, Abdalla SM, Cohen GH, Sampson L, Vivier PM, Galea S. Prevalence of depression symptoms in US adults before and during the COVID-19 pandemic. JAMA Network Open. 2020; 3(9): e2019686-e2019686. DOI: https://doi. org/10.1001/jamanetworkopen.2020.19686

7. Wang J, Lloyd-Evans B, Giacco D, Forsyth R, Nebo C, Mann F, Johnson S. Social isolation in mental health: a conceptual and methodological review. Social Psychiatry and Psychiatric Epidemiology. 2017 Dec; 52(12): 1451-61. DOI: https://doi.org/10.1007/s00127-017-1446-1

8. American Psychological Association. Clinical practice guideline for the treatment of depression across three age cohorts. Washington, DC: Author. 2019.

9. Depression NI. The treatment and management of depression in adults (partial update of NICE clinical guideline 23). London: National Institute for Clinical Excellence. 2009.

10. Taylor RW, Marwood L, Oprea E, DeAngel V, Mather S, Valentini B, Zahn R, Young AH, Cleare AJ. Pharmacological augmentation in unipolar depression: a guide to the guidelines. International Journal of Neuropsychopharmacology. 2020 Sep; 23(9): 587-625. DOI: https://doi.org/10.1093/ijnp/pyaa033

11. Cuijpers P, Karyotaki E, Ciharova M, Miguel C, Noma H, Furukawa TA. The effects of psychotherapies for depression on response, remission, reliable change, and deterioration:
A meta-analysis. Acta Psychiatrica Scandinavica. 2021 Jun

9. DOI: https://doi.org/10.1111/acps.13335

12. Cuijpers $P$, Noma $H$, Karyotaki E, Vinkers $\mathrm{CH}$, Cipriani A, Furukawa TA. A network metaanalysis of the effects of psychotherapies, pharmacotherapies and their combination in the treatment of adult depression. World Psychiatry. 2020 Feb; 19(1): 92-107. DOI: https://doi. org/10.1002/wps.20701

13. Arnaez JM, Krendl AC, McCormick BP, Chen Z, Chomistek AK. The association of depression stigma with barriers to seeking mental health care: A cross-sectional analysis. Journal of Mental Health. 2020; 29(2): 182-190. DOI: https://doi.org/10.1080/09638237.2019.1644494

14. Boschloo L, Bekhuis E, Weitz ES, Reijnders M, DeRubeis RJ, Dimidjian S, Dunner DL, Dunlop BW, Hegerl U, Hollon SD, Jarrett RB. The symptom-specific efficacy of antidepressant medication vs. cognitive behavioral therapy in the treatment of depression: results from an individual patient data meta-analysis. World Psychiatry. 2019; 18(2): 183-191. DOI: https://doi.org/10.1002/wps.20630

15. Chekroud AM, Foster D, Zheutlin AB, Gerhard DM, Roy B, Koutsouleris N, Chandra A, Esposti MD, Subramanyan G, Gueorguieva R, Paulus M. Predicting barriers to treatment for depression in a US national sample: a cross-sectional, proof-of-concept study. Psychiatric Services. 2018; 69(8): 927-934. DOI: https://doi.org/10.1176/appi.ps.201800094

16. Szlyk H, Deng J, Xu C, Krauss MJ, Cavazos-Rehg PA. Leveraging social media to explore the barriers to treatment among individuals with depressive symptoms. Depression and Anxiety. 2020; 37(5): 458-465. DOI: https:// doi.org/10.1002/da.22990

17. Substance Abuse and Mental Health Services Administration. Key substance use and mental health indicators in the United States: Results from the 2019 National Survey on Drug Use and Health. 2020.

18. Olfson M, Blanco C, Marcus SC. Treatment of adult depression in the United States. JAMA Internal Medicine. 2016; 176(10): 1482-1491. DOI: https://doi.org/10.1001/ jamainternmed.2016.5057

19. Wang, PS, Berglund, PA, Olfson, M, Kessler, RC. Delays in initial treatment contact after first onset of a mental disorder. Health Services Research. 2004; 39(2): 393-416. DOI: https://doi.org/10.1111/j.1475-6773.2004.00234.x

20. Alonso J, Angermeyer MC, Bernert S, Bruffaerts R, Brugha TS, Bryson $\mathbf{H}$, et al. Prevalence of mental disorders in Europe: results from the European Study of the Epidemiology of Mental Disorders (ESEMeD) project. Acta Psychiatrica Scandinavica. 2004; 109: 21-27. DOI: https:// doi.org/10.1111/j.1600-0047.2004.00325.x

21. Frank E, Prien RF, Jarrett RB, Keller MB, Kupfer DJ, Lavori PW, et al. Conceptualization and rationale for consensus definitions of terms in major depressive disorder. Remission, recovery, relapse, and recurrence. Archives of General Psychiatry. 1991; 48: 851-5. DOI: https://doi. org/10.1001/archpsyc.1991.01810330075011 
22. Kessler RC, Chiu WT, Demler O, Merikangas KR, Walters EE. Prevalence, severity, and comorbidity of 12-month DSM-IV disorders in the National Comorbidity Survey Replication. Archives of General Psychiatry. 2005; 62: 61727. DOI: https://doi.org/10.1001/archpsyc.62.6.617

23. Scholten WD, Batelaan NM, Penninx BWJH, van Balkom AJLM, Smit JH, Schoevers RA, et al. Diagnostic instability of recurrence and the impact on recurrence rates in depressive and anxiety disorders. Journal of Affective Disorders. 2016; 195: 185-90. DOI: https://doi.org/10.1016/j. jad.2016.02.025

24. Saha K, Torous J, Kiciman E, De Choudhury M. Understanding Side Effects of Antidepressants: Largescale Longitudinal Study on Social Media Data. JMIR mental health. 2021 Mar 19; 8(3): e26589. DOI: https://doi. org/10.2196/26589

25. Milan R, Vasiliadis HM. The association between side effects and adherence to antidepressants among primary care community-dwelling older adults. Aging \& Mental Health. 2020; 24(8): 1229-1236. DOI: https://doi.org/10.108 0/13607863.2019.1594165

26. Carleton KE, Patel UB, Stein D, Mou D, Mallow A, Blackmore MA. Enhancing the scalability of the collaborative care model for depression using mobile technology. Translational Behavioral Medicine. 2020; 10(3): 573-579. DOI: https://doi.org/10.1093/tbm/ibz146

27. Wosik J, Fudim M, Cameron B, Gellad ZF, Cho A, Phinney D, Curtis S, Roman M, Poon EG, Ferranti J, Katz JN. Telehealth transformation: COVID-19 and the rise of virtual care. Journal of the American Medical Informatics Association. 2020 Jun; 27(6): 957-62. DOI: https://doi. org/10.1093/jamia/ocaa067

28. Moreno C, Wykes T, Galderisi S, Nordentoft M, Crossley N, Jones N, Cannon M, Correll CU, Byrne L, Carr S, Chen EY. How mental health care should change as a consequence of the COVID-19 pandemic. The Lancet Psychiatry. 2020 Jul 16. DOI: https://doi.org/10.1016/S2215-0366(20)30307-2

29. Torous J, Myrick KJ, Rauseo-Ricupero N, Firth J. Digital mental health and COVID-19: using technology today to accelerate the curve on access and quality tomorrow. JMIR mental health. 2020 Mar 26; 7(3): e18848. DOI: https://doi. org/10.2196/18848

30. Thomas KC, Ellis AR, Konrad TR, Holzer CE, Morrissey JP. County-level estimates of mental health professional shortage in the United States. Psychiatric Services. 2009 Oct; 60(10): 1323-8. DOI: https://doi.org/10.1176/ ps.2009.60.10.1323

31. Barnett ML, Huskamp HA. Telemedicine for mental health in the United States: Making progress, still a long way to go. Psychiatric Services. 2020; 71(2): 197-198. DOI: https://doi. org/10.1176/appi.ps.201900555

32. BlueShield, BlueCross. 2018. Major Depression: The Impact on Overall Health. https://www.bcbs.com/ the-health-of-america/reports/major-depression-theimpact-overall-health. Accessed September 27, 2020.
33. Rahimi, K. Digital health and the elusive quest for cost savings. The Lancet Digital Health. 2019; 1(3): e108-e109. DOI: https://doi.org/10.1016/S2589-7500(19)30056-1

34. Mohr D, Cuijpers P, Lehman K. Supportive accountability: a model for providing human support to enhance adherence to eHealth interventions. Journal of Medical Internet Research. 2011; 13(1): e30. DOI: https://doi.org/10.2196/jmir.1602

35. Patel S, Akhtar A, Malins S, Wright N, Rowley E, Young E, Sampson S, Morriss R. The acceptability and usability of digital health interventions for adults with depression, anxiety, and somatoform disorders: Qualitative systematic review and meta-synthesis. Journal of Medical Internet Research. 2020; 22(7): e16228. DOI: https://doi. org/10.2196/16228

36. Richards D, Richardson T. Computer-based psychological treatments for depression: a systematic review and metaanalysis. Clinical Psychology Review. 2012; 32(4): 329-342. DOI: https://doi.org/10.1016/j.cpr.2012.02.004

37. Lattie EG, Adkins EC, Winquist N, Stiles-Shields C, Wafford QE Graham AK. Digital mental health interventions for depression, anxiety, and enhancement of psychological well-being among college students: Systematic review. Journal of Medical Internet Research. 2019; 21(7): e12869. DOI: https://doi.org/10.2196/12869

38. Economides M, Ranta K, Nazander A, Hilgert O, Goldin PR, Raevuori A, Forman-Hoffman V. Long-Term Outcomes of a Therapist-Supported, Smartphone-Based Intervention for Elevated Symptoms of Depression and Anxiety: Quasiexperimental, Pre-Postintervention Study. JMIR mHealth and uHealth. 2019; 7(8): e14284. DOI: https://doi. org/10.2196/14284

39. Cook JE, Doyle C. Working alliance in online therapy as compared to face-to-face therapy: Preliminary results. Cyber Psychology \& Behavior. 2002; 5(2): 95-105. DOI: https://doi.org/10.1089/109493102753770480

40. Katzelnick DJ, Duffy FF, Chung H, Regier DA, Rae DS, Trivedi MH. Depression outcomes in psychiatric clinical practice: using a self-rated measure of depression severity. Psychiatric Services. 2011; 62(8): 929-935. DOI: https://doi. org/10.1176/ps.62.8.pss6208_0929

41. Rush AJ, Trivedi M, Carmody TJ, Biggs MM, Shores-Wilson K, Ibrahim H, Crismon ML. One-year clinical outcomes of depressed public sector outpatients: a benchmark for subsequent studies. Biological Psychiatry. 2004; 56(1): 46-53. DOI: https://doi.org/10.1016/j.biopsych.2004.04.005

42. Hartmann R, Sander C, Lorenz N, Böttger D, Hegerl U. Utilization of Patient-Generated Data Collected Through Mobile Devices: Insights From a Survey on Attitudes Toward Mobile Self-Monitoring and Self-Management Apps for Depression. JMIR Mental Health. 2019; 6(4): e11671. DOI: https://doi.org/10.2196/11671

43. Kopelovich SL, Monroe-DeVita M, Buck BE, Brenner C, Moser L, Jarskog LF, Harker S, Chwastiak LA. Community mental health care delivery during the COVID-19 pandemic: practical strategies for improving care for people with 
serious mental illness. Community Mental Health Journal. 2021 Apr; 57(3): 405-15. DOI: https://doi.org/10.1007/ s10597-020-00662-z

44. Bickman L. Improving mental health services: A 50-year journey from randomized experiments to artificial intelligence and precision mental health. Administration and Policy in Mental Health and Mental Health Services Research. 2020 Sep; 47(5): 795-843. DOI: https://doi. org/10.1007/s10488-020-01065-8

45. Bernert RA, Hilberg AM, Melia R, Kim JP, Shah NH,

Abnousi F. Artificial intelligence and suicide prevention: a systematic review of machine learning investigations. International journal of environmental research and public health. 2020 Jan; 17(16): 5929. DOI: https://doi. org/10.3390/ijerph17165929

46. Rezaii N, Walker E, Wolff P. A machine learning approach to predicting psychosis using semantic density and latent content analysis. NPJ schizophrenia. 2019 Jun 13; 5(1): 1-2. DOI: https://doi.org/10.1038/s41537-019-0077-9

47. Ni Y, Barzman D, Bachtel A, Griffey M, Osborn A, Sorter

M. Finding warning markers: leveraging natural language processing and machine learning technologies to detect risk of school violence. International journal of medical informatics. 2020 Jul 1; 139: 104137. DOI: https://doi. org/10.1016/j.ijmedinf.2020.104137

48. Kroenke K, Spitzer RL, Williams JB. The PHQ9: validity of a brief depression severity measure. Journal of general internal medicine. 2001 Sep; 16(9): 606-13. DOI: https://doi. org/10.1046/j.1525-1497.2001.016009606.x

49. Sheehan DV, Lecrubier Y, Sheehan KH, Amorim P, Janavs J, Weiller E, Hergueta T, Baker R, Dunbar GC. The MiniInternational Neuropsychiatric Interview (MINI): the development and validation of a structured diagnostic psychiatric interview for DSM-IV and ICD-10. Journal of clinical psychiatry. 1998 Jan 1; 59(20): 22-33

50. Rauschenberg C, Schick A, Hirjak D, Seidler A, Paetzold I, Apfelbacher C, Riedel-Heller SG, Reininghaus U. Evidence synthesis of digital interventions to mitigate the negative impact of the COVID-19 pandemic on public mental health: rapid meta-review. Journal of medical Internet research. 2021 Mar 10; 23(3): e23365. DOI: https://doi. org/10.2196/23365

\section{TO CITE THIS ARTICLE:}

Forman-Hoffman VL, Kvedar JC, Ranta K. Potential Benefits of Remote Continuous Care for Depression. International Journal of Digital Health. 2021; 1(1): 15, 1-6. DOI: https://doi.org/10.29337/ijdh.39

Submitted: 29 June 2021 Accepted: 27 August 2021 Published: 13 September 2021

\section{COPYRIGHT:}

(c) 2021 The Author(s). This is an open-access article distributed under the terms of the Creative Commons Attribution-NonCommercial 4.0 International License (CC-BY-NC 4.0), which permits unrestricted distribution, reproduction and adaptation in any medium, provided the original author and source are credited, and that the material is not used for commercial purposes. See https://creativecommons.org/licenses/by-nc/4.0/.

International Journal of Digital Health is a peer-reviewed open access journal published by IJS Publishing Group. 